\title{
Advances in Magnetic Nanoparticle-Driven Delivery of Gene Therapies towards Prostate Cancer
}

\author{
Raju Panday $\mathbb{D}^{1},{ }^{1}$ Ahmed M. E. Abdalla, ${ }^{1,2}$ Manisha Neupane, ${ }^{3}$ Sujan Khadka, ${ }^{4,5}$ \\ Aymane Kricha, ${ }^{1}$ and Guang Yang ${ }^{1}$ \\ ${ }^{1}$ Department of Biomedical Engineering, College of Life Science and Technology, Huazhong University of Science and Technology, \\ Wuhan 430074, China \\ ${ }^{2}$ Department of Biochemistry, College of Applied Science, University of Bahri, 1660/11111, Khartoum, Sudan \\ ${ }^{3}$ Department of Biotechnology, National Institute of Science and Technology, Sorakhutte, Kathmandu 44600, Nepal \\ ${ }^{4}$ State Key Laboratory of Environmental Aquatic Chemistry, Research Center for Eco-Environmental Sciences, Chinese Academy \\ of Sciences, Beijing 100085, China \\ ${ }^{5}$ University of Chinese Academy of Sciences, Beijing 100049, China
}

Correspondence should be addressed to Raju Panday; raju.panday@hotmail.com

Received 8 June 2021; Accepted 23 August 2021; Published 15 September 2021

Academic Editor: Donglu Shi

Copyright (C) 2021 Raju Panday et al. This is an open access article distributed under the Creative Commons Attribution License, which permits unrestricted use, distribution, and reproduction in any medium, provided the original work is properly cited.

\begin{abstract}
Conventional treatment possibilities for one of the most common diseases among men, i.e., prostate cancer has several side effects. Gene-based therapy such as siRNA, CRISPR/Cas9, pDNA, and miRNA have emerged as an alternative, combating posttherapy side effects and drug resistance. Magnetic nanoparticles have been appropriately modified and functionalized to efficiently deliver the gene therapy-based active compounds to prostate tumor cells. The main purpose of this review article is to highlight the strategies currently being utilized for the treatment of prostate cancer using magnetic nanoparticles for delivery of genetic material using both the passive and active (ligand-based) targeting. It further discusses the challenges in efficient delivery of therapeutics to tumor sites and their remedial approaches. Finally, it provides a glimpse of future advances for tumor-specific modifications of magnetic nanoparticles to combat prostate cancer.
\end{abstract}

\section{Introduction}

Other than lung cancer, prostate cancer $(\mathrm{PCa})$ is the most common cancer among men, especially in the developed world $[1,2]$. It is the second most prevalent cause of mortality among males in the USA [2]. Since the disease is caused by accumulation of mutations in normal prostate cells and conferring them malignant phenotype, treatment strategies depend on the stage of PCa in the body. The conventional strategies for the treatment are surgery, chemotherapy, radiation therapy, and hormone therapy [3]. If the cancer is confined, chemotherapy can be utilized for treatment $[4,5]$. However, the lack of specificity, systemic toxicity, and development of drug resistance in tumor cells limits the uses of chemotherapy [6]. Radical prostatectomy (RP) and radiation therapy (RT) are another choices for treatment [7] especially, for the most common localized prostate cancer [8]. But these types of treatment can be relatively unsafe, unreliable, cause sexual and urinary dysfunctions, and may induce drug resistance [9].

However, the first-line therapy for improving the survival and reducing the morbidity in primary metastatic prostate cancer is the androgen-deprivation therapy (ADT) also known as called hormonal therapy $[10,11]$. It is the primary method of treatment for metastatic prostate and the relapsed cancer [3]. Its aim is to control the cancer by lowering the levels of blood testosterone on which the tumor cells are dependent for survival and are achieved by using antiandrogens, luteinizing hormone-releasing hormone (LHRH) antagonists and LHRH agonists [12, 13]. However, these treatment measures are not specific for PCa and cause side effects which can be serious with chances of recurrence of 
more aggressive androgen-independent form called castrateresistant prostate cancer (CRPC) [14, 15]. Treatment for CRPC after ADT is very difficult because of the slow decline in treatment efficacy [2].

Therefore, eradication of prostate cancer has especially been challenging due to its highly heterogeneous and specific nature. To improve the efficiency of conventional drugs, nanocarriers and nanoparticles have been developed for delivery purposes [16]. Recently, a large number of antiprostate cancer drug delivery approaches have been proposed [17]. For instance, chemotherapeutic prostate cancer drugs such as paclitaxel and docetaxel can be delivered in high doses to specifically target prostate tumor, avoiding many side effects on normal cells [11].

However, unlike the conventional therapeutic delivery methods, gene delivery using nucleic acids has many advantages such as being usable in nondruggable targets $[15,18]$. Moreover, nucleic acids are highly specific and act rapidly with higher potency [19]. Knockdown or activation of different types of oncogenes and tumor suppressor genes has shown potential results in prostate cancer treatment. Magnetic nanoparticles can also function as MRI contrast agent for imaging the solid tumors such as prostate tumor [20]. With so many different roles from being delivery vehicles to MRI contrast agent, this review specifically highlights the potential applications of magnetic nanoparticles in prostate cancer gene therapy. It also discusses the techniques used for targeted delivery and sheds light on various obstacles for gene delivery along with their possible mitigation approaches.

\section{Magnetic Nanoparticles for Gene Therapy}

The great potential benefit of gene therapy lies in the disease treatment of genetic disorders, viral infections, and cancer. Recently, different types of magnetic nanoparticles have been developed for cancer diagnosis and treatment [21]. Their dimension makes them an ideal candidate for surface functionalization. These modifications form the basis of highly diverse pharmaceutical and biomedical applications, such as diagnosis, drug delivery, gene delivery, and enzyme delivery [22]. Magnetic nanoparticles have received considerable attention, in order to develop an efficient delivery system to carry in vivo drugs and other active compounds. Since magnetic nanoparticles can be catered to below $100 \mathrm{~nm}$ size, their special characteristics like higher surfacevolume ratio, large surface energy, and high reactivity permits them to have potential applications in biomedical fields [23]. Despite all these benefits, very few magnetic nanoparticles have been used in clinical practice partly because of limited research in this field. However, some magnetic nanoparticles are currently in early clinical trials for medical imaging purpose (Table 1).

Both the viral-based and nonviral-based delivery vehicles have been employed for gene therapy treatment of prostate cancer. The most common viral vectors currently being used include adenovirus, adeno-associated virus, pox virus, retrovirus, herpes simplex virus, and lentivirus, whereas the nonviral-based vectors mostly used are polymer-based nanoparticles or nanocarriers [24-26]. These vectors can be easily modified to develop different types of therapeutic systems, and their efficiency and safety are also being evaluated in clinical trials.

\section{Delivery Systems}

Iron oxide nanoparticles have been better suited as MRI agents as compared to gadolinium-based MRI agents based on their lower toxicity, lower detection limit, and stronger proton relaxation features [27]. There are two types by which magnetic nanoparticles can be targeted to the tumor site, namely, active and passive targeting. In passive targeting, the magnetic nanoparticles are accumulated to the required tumor site by enhanced permeability and retention (EPR) effect caused by leaky blood vasculature and dysfunctional lymph system [22]. The accumulation highly depends on the size of magnetic nanoparticles, pore size of leaky blood vessels, and the half-life of nanoparticles in blood circulation. For active targeting, magnetic nanoparticles are modified with some specific targeting molecules such as ligands, antibodies, and peptides depending on the type of tumor and its target tissue expressing a specific surface receptor.

There are various methods of delivery; here, we discuss about targeted delivery using external magnet and specific ligands for prostate cancer.

3.1. Targeted Delivery Using External Magnet. Magnetic nanoparticles can be externally controlled to guide the nanoparticles to specific solid tumor/tissues and used for imaging the tumor. This feature is more restricted to diagnosis and imaging of tumor in specific tissue (Figure 1). For this purpose, a specific concentration of Fe in MNPs is injected into the body, and then, after guiding the nanoparticles to a specific tumor site using external magnet, the tumor is imaged for which the contrast is provided by the iron oxide nanoparticles. For example, ferumoxtran-10, a dextran-coated MNP which has a mean size of about $30 \mathrm{~nm}$, is in phase III clinical trials for diagnosis of prostate cancer [28]. Its sensitivity and specificity are $90.5 \%$ and $97.8 \%$, respectively, for detecting the prostate cancer lymph node disease. It functions by passively accumulating in the metastatic lymph nodes of prostate cancer.

Similarly, another application of magnetic nanoparticles includes the guided photothermal therapy of tumor itself. External magnets can be used to guide the magnetic nanoparticles into their specific location, and then, the drug release can be controlled photothermally using a near infrared or infrared light generating heat in the nanoparticles and releasing the drug bound to them [29]. These externally triggered drug release could accumulate in the tumor site due to the EPR effect. One study revealed the optimum size of $\mathrm{Fe}_{3} \mathrm{O}_{4}$ nanoparticles to be $220 \mathrm{~nm}$ resulting in higher temperature and better therapeutic effect [21]. In another study, magnetic carbon nanoparticles were used for photothermal delivery of dyes and plasmids [30]. The irradiated nanoparticles with NIR laser beam causes rise in temperature allowing for internalization inside the cells. An improved gene 
TABLE 1: Magnetic nanoparticles approved for clinical trials for medical imaging and diagnosis.

\begin{tabular}{|c|c|c|c|c|c|}
\hline $\begin{array}{l}\text { Drug/ } \\
\text { nanoparticle }\end{array}$ & Drug & $\begin{array}{c}\text { Trial } \\
\text { phase }\end{array}$ & Treatment/diagnosis & Application & NCT no. \\
\hline [18]F DCFPyL & [18]F DCFPyL, enzalutamide, abiraterone & 4 & Prostate cancer & $\begin{array}{l}\mathrm{PET} / \mathrm{CT} \\
\text { scan }\end{array}$ & 03860987 \\
\hline [18]F-fluciclovine & [18]F-fluciclovine & 2 & Prostate cancer & PET/MRI & 03264456 \\
\hline [18]F-FDG & Enzalutamide & 2 & $\begin{array}{c}\text { Castration-resistant prostate } \\
\text { cancer }\end{array}$ & $\mathrm{PET} / \mathrm{CT}$ & 02814968 \\
\hline $\begin{array}{l}\text { Hybrid C11- } \\
\text { choline }\end{array}$ & Gadobutrol and C-11 choline & 3 & Prostate cancer & PET/MRI & 03404648 \\
\hline Ga38 PSMA-11 & Gallium Ga68-PSMA & 3 & Stage II and III prostate cancer & $\mathrm{PET} / \mathrm{MRI}$ & 02678351 \\
\hline Ga68-RM2 & $\begin{array}{c}\text { Gallium Ga68-labeled GRPR antagonist } \\
\text { BAY86-7548 }\end{array}$ & 3 & Prostate cancer & PET/MRI & 02624518 \\
\hline
\end{tabular}

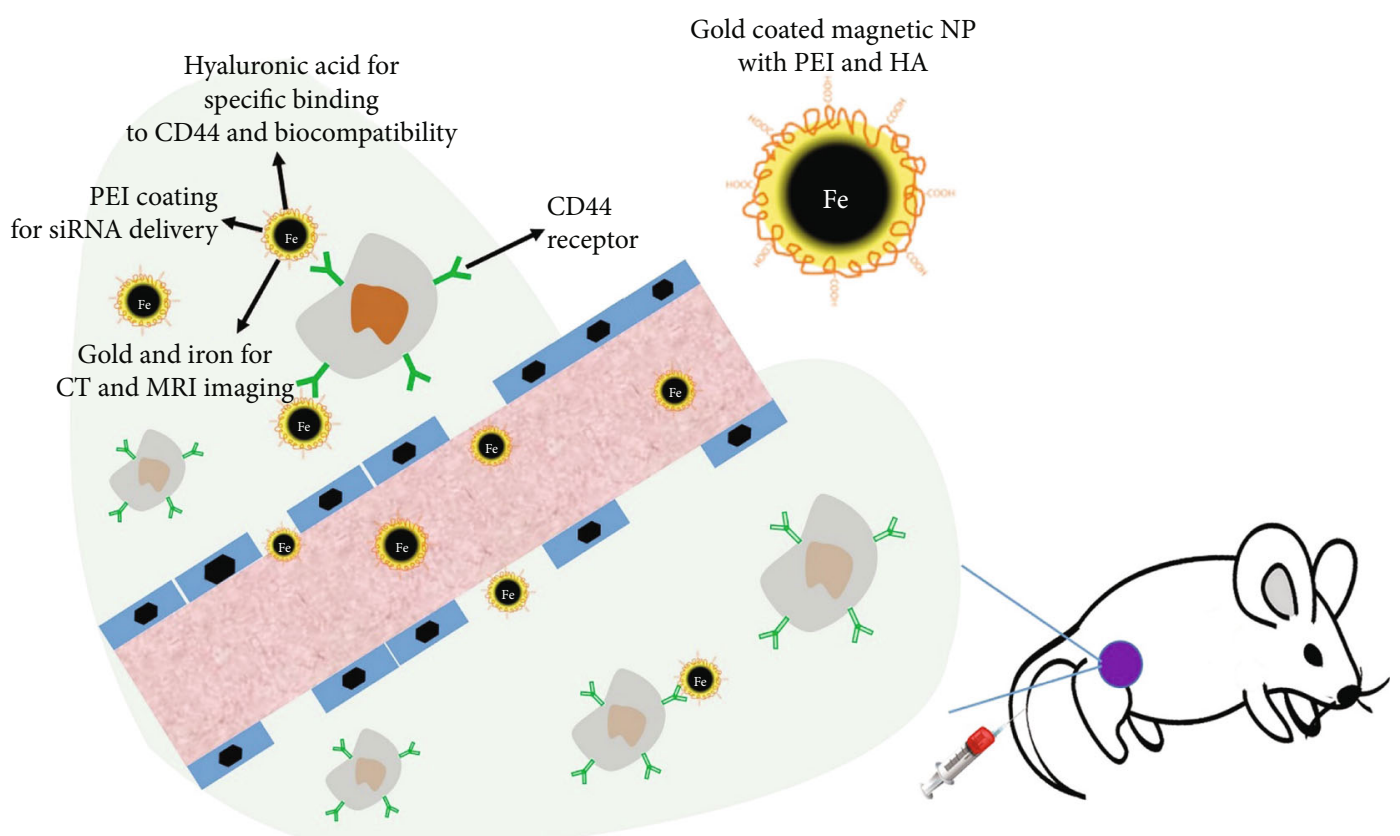

FIGURE 1: Design of CD44-targeted HA-PEI- $\mathrm{Fe}_{3} \mathrm{O}_{4} / \mathrm{Au}$ nanoparticles for CT and MRI imaging.

delivery system was developed using the photothermal delivery composed of liposomal carbon dots nanohybrids (PEG$\mathrm{Fe} / \mathrm{CDs}$ ) and showed about $16^{\circ} \mathrm{C}$ temperature rise after 5 min of irradiation of the tumor tissue [31].

\subsection{Nonmagnetic (Ligand-Based) Targeting. More specific} than the passive targeting, active targeting involves the modification of nanoparticles with some specific ligand molecules such as folic acid, sugars, RGD peptides, antibodies, and hyaluronic acid which then bind to their specific receptor molecule in the tumor cell (Table 2) [32, 33]. Highly overexpressed receptor targeting makes this method more specific towards one specific type of cancer. For example, HSP-70-linked magnetic nanoparticles are capable of attaching to CD40 receptors which is expressed on glioma cells [34].

For diagnosis of prostate cancer, one of the most common targeting molecules is prostate-specific membrane antigen (PSMA) which can be targeted via antibody.
PSMA is an ideal target for prostate cancer, specifically produced and expressed in prostate cancer [44]. In one study, magnetic nanoparticles were conjugated to PSMAtargeting antibody, J591, for targeting prostate cancer [43]. The J591-bound magnetic NPs enhanced the cellular iron uptake. MRI of tumors was enhanced in vivo when using PSMA-targeting NPs as compared to nontargeted NPs. Therefore, they provided a proof that PSMAtargeting can be a potential mode for enhancing the MRI of prostate cancer.

\section{Delivery of Different Gene Therapy by MNPs}

Magnetic nanoparticles after functionalization with nucleic acid carrier can be used for delivering different types of nucleic acids (Figure 2). Here, we discuss the recent strategies on how these nanoparticles can be utilized in various applications and strategies. 
TABLE 2: Different types of magnetic nanoparticles and their application in treatment and diagnosis of cancer.

\begin{tabular}{|c|c|c|c|c|c|c|}
\hline Type of MNP & Drug/gene & Target gene & Route & Mouse model & Application & Reference \\
\hline $\begin{array}{l}\text { PEG-Ga }{ }^{68} \text {-Lys- } \\
\text { urea-Glu }\end{array}$ & DM1 & PSMA & i.v. & $\begin{array}{l}\text { SCID mice with PC3-PIP and } \\
\text { PC3-flu tumors }\end{array}$ & $\begin{array}{l}\text { PET/CT scan and } \\
\text { therapy }\end{array}$ & {$[35]$} \\
\hline MNP-PEI-PEG & - & Folate receptor & i.v. & $\mathrm{Balb} / \mathrm{c}$ nude mice & MRI & {$[36]$} \\
\hline MNP-PCL & Gemcitabine & - & i.v. & Xenograft mice & $\begin{array}{l}\text { Pancreatic cancer } \\
\text { treatment }\end{array}$ & {$[37]$} \\
\hline MNP-alginate & - & - & i.v. & Xenograft mice & MRI & {$[38]$} \\
\hline MNP-PEI-PEG & & $\begin{array}{l}\text { PSCA (prostate stem cell } \\
\text { antigen) }\end{array}$ & - & - & $\begin{array}{l}\text { Prostate cancer } \\
\text { targeting in vitro }\end{array}$ & {$[39]$} \\
\hline MNP-citrate & - & - & i.v. & Hepatic fibrosis Wistar rats & MRI of liver & {$[40]$} \\
\hline $\begin{array}{l}\text { MNP-soybean } \\
\text { oil }\end{array}$ & - & - & Nasal & CD-1 female mice & MRI of nasal septum & {$[41]$} \\
\hline MNP-Au-HA & - & CD44 & $\begin{array}{l}\text { i.v., } \\
\text { i.t. }\end{array}$ & $\mathrm{Balb} / \mathrm{c}$ nude mice & $\begin{array}{c}\text { MRI, CT and } \\
\text { photothermal therapy }\end{array}$ & {$[42]$} \\
\hline MNP-CD-J591 & Docetaxel & $\begin{array}{l}\text { PSMA (prostate specific } \\
\text { membrane antigen) }\end{array}$ & i.v. & C4-2 and PC3 tumor mice & $\begin{array}{l}\text { Prostate cancer } \\
\text { treatment }\end{array}$ & {$[43]$} \\
\hline
\end{tabular}

MNP: magnetic nanoparticles; i.v.: intravenous; i.t.: intratumoral; PSCA: prostate stem cell antigen; PSMA: prostate-specific membrane antigen.
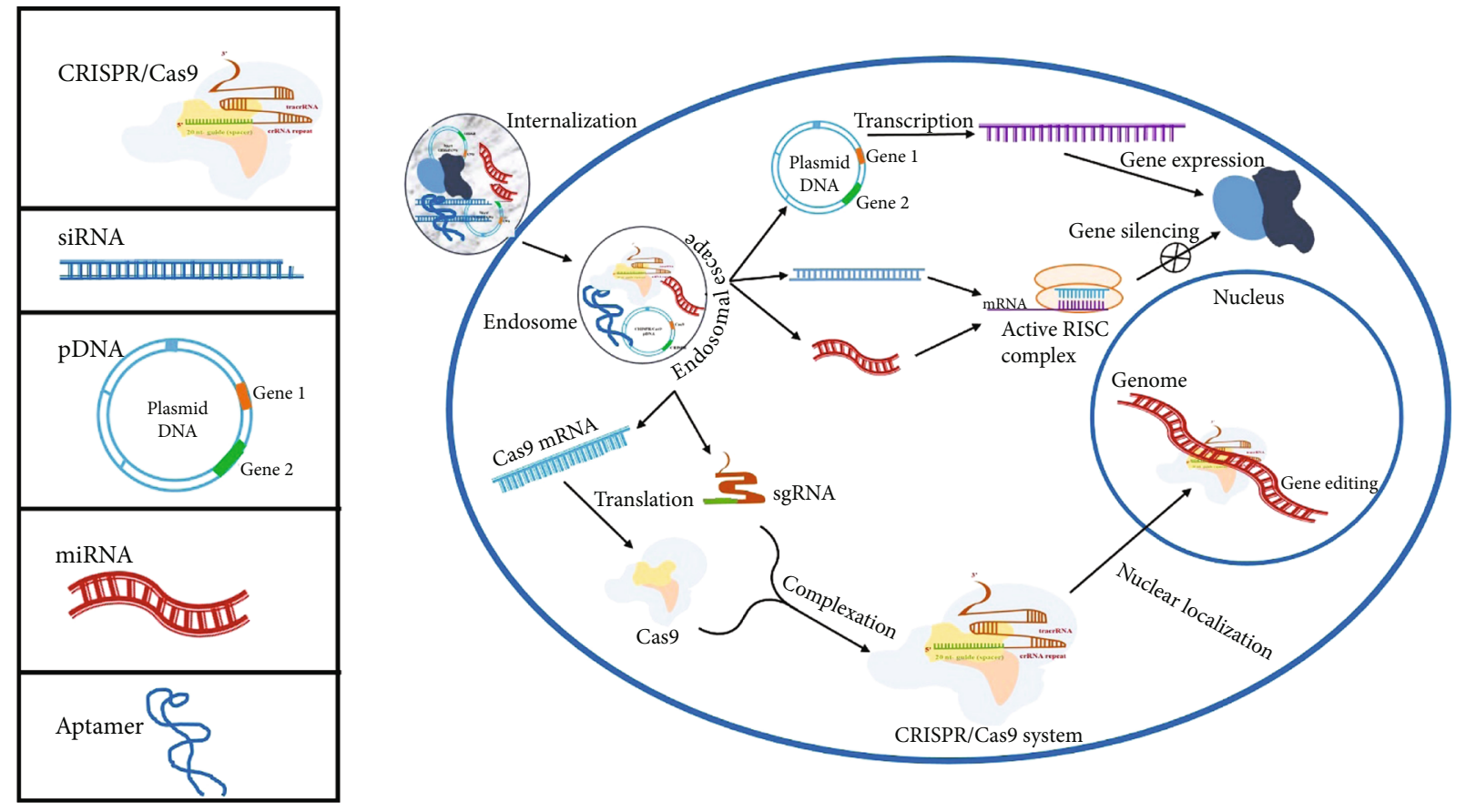

Figure 2: Different types of gene therapy systems that are being investigated for delivery using magnetic nanoparticles. A simplified overview of the various mechanisms with which these systems act upon internalization inside the cells. All the systems act in the cytosol except for CRISPR/Cas9 system which localizes in nucleus.

4.1. siRNA-Based Gene Therapy of Prostate Cancer. In recent years, different strategies have been developed for treatment of prostate cancer using siRNA-based gene therapy $[45,46]$. siRNA against different genes have been utilized for gene silencing purpose to inhibit cellular function [47].

For instance, Wang and coworkers, modified magnetic nanoparticles with PEI to develop a multifunctional nanocarrier for both MRI as well as in vitro gene therapy of cancer cells [48]. They constructed a surviving siRNA-PEIMNP delivery system which efficiently inhibited cellular proliferation and induced apoptosis and autophagy of glioblastoma multiforme (U251) cells. The major function of cationic polymer such as PEI used in this study is to effectively absorb siRNA via electrostatic interaction and thereby protecting from enzymatic degradation in vitro. In another study, glycol chitosan-based nanoparticles also acted as an efficient delivery vehicle for encapsulating siRNA along with a chemotherapeutic drug to accomplish maximum efficiency for overcoming the drug resistance [49]. In this study, Bcl-2 siRNA-loaded and DOX-loaded glycol chitosan NPs both 
showed quite similar physiochemical features such as size, surface properties, and $\mathrm{pH}$ sensitive behavior. Both nanodelivery vehicles showed similar in vivo biodistribution and pharmacokinetics and enhanced treatment in a dosedependent manner.

Instead of delivering the siRNA directly to cells, attaching a specific receptor can specifically target tumor cells for silencing of target genes. For example, folate receptor (FR) is a target specifically overexpressed in tumor cells. In a study conducted by Biswal and coworkers, dihydrofolate reductase (DHFR) siRNA expressing-plasmid was complexed with folate-polyethylene glycol-polyethylenimine (PEI-PEG-Fol) and delivered into FR positive human epidermal carcinoma (KB) cells as well as FR negative A549 cells [50]. It was shown that siRNA was delivered inside the KB cells where it inhibited the DHFR gene expression, whereas A549 cells were unable to uptake the siRNAnanocomplex. They concluded that DHFR siRNA complexed with PEG-PEI-Fol can be specifically taken up by FR positive cells which makes them highly specific delivery vehicles. This strategy is designed for particular cancer types; however, it can be extended to various tissue treatment deliveries.

There are still some bottlenecks facing nonviral delivery of siRNA which hinder the successful application in vivo [51]. In one study, PEI-based siRNA delivery system was developed to protect the siRNA from nucleolytic enzyme degradation while delivering to specific tissue $[52,53]$. They modified PEI by noncovalently attaching phospholipid liposomes which decreased the cytotoxicity and at the same time increased the delivery efficiency of siRNA.

Functionalization of low molecular weight PEI with tyrosine can also improve the biocompatibility, stability, and silencing efficacy of modified nanoparticles [54]. If ligand-mediated cellular uptake is required, PEI can be conjugated with PEG to shield surface charges of PEI, prior to coupling a ligand such as anti-HER1 antibody for targeted delivery [52, 55]. The analyses are also extended beyond tumor cell lines, involving tumor xenograft tissues which reflect more convincingly the in vivo experiment. This is evident by the siRNA-mediated silencing of target genes, i.e., surviving and HER2 in intact tissue and stroma revealing nanoparticle penetration and cellular efficacy. Liposomes containing iron oxide nanoparticles can also work as a heating element for temperature-triggered drug release [56]. In one study, 1,2-dipalmitoyl-sn-glycero-3-phosphocholine (DPPC) and cholesterol-containing thermosensitive magnetic carrier was developed for codelivery of drug doxorubicin as well as shRNA (to target special AT-rich binding protein (SATB1) into gastric tumor cells [57]. SATB1, also known as genome organizer, is involved in regulation of malignant biological behavior of many cancers, and its knockdown can lead to reduce cell proliferation, metastasis, and induction of apoptosis. DPPC is thermosensitive which causes liposomes to change from gel to liquid phase at higher temperatures $\left(41^{\circ} \mathrm{C}\right)$, thereby increasing permeability for drug release. This study showed that there was higher tumor inhibition when DOX and SATB1 were codelivered with magnetic targeting to the tumor site than other single formulations.
4.2. CRISPR/Cas9-Based Gene Therapy of Prostate Cancer. Clustered regularly interspaced short palindromic repeats (CRISPR) was identified for the first time in bacteria which encode CRISPR RNAs to guide CRISPR-associated (Cas) nucleases by invading genetic material and act as adaptive immune response system [58-60]. Later, type II CRISPR/Cas9 system of $S$. pyogens which is similar to eukaryotic CRISPR system, was also discovered and mostly chosen for different applications in gene expression regulation due to its highly efficient DNA-targeting system [60]. To locate the site-specific DNA sequence, gRNA was used by Cas9 to form base pairs and then introduced as a double strand break [61]. The first 20 nucleotides of gRNA can be altered to direct Cas9 to specific site providing unique flexibility and accessibility for DNA editing [60]. The most common method, i.e., the direct delivery of Cas9 protein along with sgRNA, is the easiest method of genome editing since there is no requirement for transcription or translation [62]. Because of larger size of Cas9 protein $(160 \mathrm{kD})$ along with its positive charge and the negative charge of sgRNA, there is major problem associated with the cellular delivery of the CRISPR/Cas9 complex. To alleviate Cas9 protein, an alternative use of Cas9 mRNA with sgRNA was proposed which could be easily obtained by in vitro transcription and by-passing nuclear transcription. Moreover, Cas9 mRNA rapidly initiates genome editing.

Many researches have been using CRISPR/Cas9 system for inhibition of some targeted gene to develop new therapeutics for different diseases $[63,64]$. But the major problem is the efficient and safe delivery of CRISPR/Cas9 specifically to targeted cells [62]. To solve this limitation, in one study, a flexible aptamer-liposome CRISPR/Cas9 chimera was developed to effectively combine the drug delivery and targeting [58]. This new chimera contained an RNA aptamer which specifically targets PC3 cells. The aptamers were then linked to cationic liposomes by postinjection method and were utilized to transport a specific survival gene, polo-like kinase 1based CRISPR-Cas9 in tumor cells. Their results showed a significant gene silencing activity in vitro with highly specific binding of aptamer-liposome complexes. This method describes a feasible way to deliver cell-type-specific CRISPR/Cas9 which will form the basis of therapeutic application in the long term of CRISPR/Cas9-based treatment.

4.3. pDNA-Based Gene Therapy of Prostate Cancer. Several researches have focused on delivery of plasmid DNA (pDNA) into the target tumor cells including prostate cancer [65]. In one interesting study, magnetic nanoparticles have been modified by low molecular weight linear PEI (Mw 423 and 1800) to develop an efficient and novel DNA delivery vehicle as well as transfection agent [66]. This study found that a very low $\mathrm{N} / \mathrm{P}$ ratio of 1 was efficient to increase the binding capacity of DNA when compared with PEI only. Moreover, these nanoparticles could be easily controlled and driven by an external magnetic force to specific target site. Because of low N/P ratio, very low amounts of PEI were required for DNA delivery and transfection purpose, thereby reducing the cytotoxicity of cells relative to higher PEI concentrations. This new method allowed smaller amounts of 
PEI to be effectively distributed across the surface of magnetic nanoparticles.

Another study revealed that APTES-modified silica nanoparticles can easily deliver a relatively higher ratio of nanoparticle to DNA cargo [67]. These nanoparticles have silane end which binds both, hydroxyl groups to iron oxide surface and the negatively charged DNA particles to amino groups of the molecule [68].

Similarly, APTES-modified magnetic nanoparticles have been studied for various purposes such as medical imaging and DNA delivery as well [69, 70]. In one such study, APTES-MNPs were modified with cationic polymers to develop a combo gene delivery vehicle [71]. The addition of cationic polymer increased the DNA binding capacity, improved the gene transfection ability, and also protected the DNA from degradation. With greater biocompatibility, lower cytotoxicity, and higher DNA loading capacity, the prepared delivery system can be largely utilized for wide applications especially in gene therapy.

4.4. miRNA-Based Gene Therapy. miRNAs are small, noncoding, single-stranded RNA molecules, endogenously expressed in cells which regulate the gene expression [72-74]. miRNAs regulate the gene expression by first binding to the $3^{\prime}$-UTR region and inhibiting the mRNA translation at posttranscriptional level [75]. miRNA recognizes the target via sequence complementarity of 2-8 nucleotides at $5^{\prime}$ -end of miRNA and the $3^{\prime}$ UTR region of specific mRNA $[76,77]$.

Recently, many studies have been carried out to understand the role of miRNA in gene therapy of prostate cancer. In one report, the polyarginine peptide (R11) was labeled to PEI nanoparticles for the miR-145 delivery to prostate cancer in vivo [72]. The advantage of this combination was the formation of an efficient transfection agent which could be taken up by prostate cancer. Moreover, the prepared R11PEI nanocarrier displayed very low cell toxicity. Following R11-PEI/miR-145 nanocomplex delivery, a significant inhibition of tumor growth leading to prolonged survival period was reported.

4.5. Aptamer-Based Gene Therapy. Alternative to nonprotein-based antibodies, nucleic acid aptamers can also be potentially used as targeting molecules for targeted delivery of chemotherapeutic agents. Because of their nucleic acid composition, nucleic acid-based aptamers possess some unique properties such as higher specificity, small size, easy in vitro selection, lower immunogenicity, and higher sensitivity [78-80]. As such, Hicke and Stephens have introduced the concept of "escort aptamers" as a new horizon for aptamer function [81]. Usually, aptamers are designed to target PSMA receptor in prostate cancer cells and attached to nanoparticles for specific delivery [58].

In one study, A10 RNA aptamer, a ligand for PSMA receptor in prostate cancer cells, was attached to magnetic nanoparticles for targeted therapy as well as imaging [82]. In the study, A10 aptamer was used to intercalate the doxorubicin drug into the GC sequence of aptamer. The same researchers developed a multifunctional, SPION-
TCL-A10 aptamer nanocarriers which could be used for MRI imaging of PCa detection and targeted drug delivery [83]. The A10 aptamer was composed of a $57 \mathrm{bp}$ nuclease, stabilized 2'-fluoropyrimidine, modified RNA molecule, or targeting PSMA receptor in PCa cells and was used as DOX carrier. Moreover, SPION-TCL was coated with carboxy-PEG-derived polymer which was used for MR contrast agent. The PEG coating prevented the nanoparticles from binding to proteins where its carboxyl group was used to conjugate targeting molecules such as A10 aptamer.

MRI has been utilized for diagnosis of cancer and drug delivery to specific tissue/cells in many researches [84]. Some hypoxia-induced cancer stem cells have been implicated in tumor metastasis, which have been targeted by hypoxia inducible factor la-based aptamer after conjugating with the $\mathrm{Mn}(\mathrm{II})$-modified magnetic nanoparticles $\left(\mathrm{Fe}_{3} \mathrm{O}_{4} / \mathrm{Mn}\right)$ [85]. These nanoparticles had a good biocompatibility with low toxicity and therefore could be used for enhanced T1- and T2-weighted MR images. The major advantage for these nanoparticles was their specific targeting to the HIF-1a which is expressed in cancer stem cells under hypoxic conditions.

\section{Challenges in Gene Therapy Using Nanoparticles}

There are several pathological barriers that need to be overcome before the nanoparticle can specifically deliver their active compound [86-88]. The tumor blood vessels are random and discontinuous with poor alignment of endothelial cells and fenestrations ranging from 100 to $500 \mathrm{~nm}$ in size $[89,90]$. Therefore, if the nanoparticles are sufficiently smaller, i.e., below $500 \mathrm{~nm}$, they can easily pass through the fenestrations and get accumulated in the tumor tissues [91-93]. Along with tumor endothelial vessel, there are several other barriers which need to be overcome by delivery systems (Table 3 ).

With much effort in the last few years, the challenges related to siRNA stability, delivery, immune response, and off-target effects are being slowly mitigated, and next generation of delivery systems has been developed and proposed [97]. In the last decade, owing to their avoidance of viralbased vectors and features of highly unable surface properties, shape, and size, nonviral polymer-based nanodelivery systems have gained a lot of attention especially in gene/drug delivery $[18,98]$. Recently, different nucleic acid delivery systems prepared from polymers, inorganic compounds, carbohydrates, and lipids have also been developed [99].

About four different issues have been identified that need to be solved before the gene therapy can be successful for cancer treatment [100]. They are

(i) Identify the major target genes which are critical for pathology and progression of cancer

(ii) Identify the best gene that could be therapeutically used to halt cancer progression 
TABle 3: Different types of pathological barriers and their prevention methods.

\begin{tabular}{|c|c|c|c|c|c|}
\hline $\begin{array}{l}\text { Pathological } \\
\text { barrier }\end{array}$ & Effector cells/chemicals & Effect on nanoparticles & Prevention method & $\begin{array}{l}\text { Nanoparticle } \\
\text { modification } \\
\text { required }\end{array}$ & Reference \\
\hline $\begin{array}{l}\text { Tissue } \\
\text { vasculature }\end{array}$ & $\begin{array}{c}\text { Different angiogenesis structure, } \\
\mathrm{pH} \text { value, and metabolic rate of } \\
\text { tumor tissues }\end{array}$ & $\begin{array}{l}\text { Different accessibility and } \\
\text { knockdown levels }\end{array}$ & NA & NA & {$[91,94]$} \\
\hline $\begin{array}{l}\text { Immune } \\
\text { system }\end{array}$ & TLR-3,7,8 & $\begin{array}{l}\text { Trigger innate immune } \\
\text { response }\end{array}$ & $\begin{array}{l}\text { Longer siRNA molecule } \\
\text { binding to nanoparticles }\end{array}$ & $\begin{array}{l}\text { Dicer-substrate } \\
\text { siRNA (25-30 nt } \\
\text { long) }\end{array}$ & [95] \\
\hline $\begin{array}{l}\text { Reticulo } \\
\text { endothelial } \\
\text { system }\end{array}$ & Kupfur cells, macrophages & Sequestration from circulation & $\begin{array}{l}\text { Coating biocompatible } \\
\text { polymer }\end{array}$ & $\begin{array}{l}\text { PEGylation, } \\
\text { RGD }\end{array}$ & {$[96]$} \\
\hline $\begin{array}{l}\text { Plasma and } \\
\text { tissue } \\
\text { nucleases }\end{array}$ & Nucleases and lipases & $\begin{array}{l}\text { Degradation of either } \\
\text { nanoparticle polymer and/or } \\
\text { RNAi drug (siRNA) }\end{array}$ & Increase circulation time & PEGylation & [53] \\
\hline $\begin{array}{l}\text { Endosomes } \\
\text { and } \\
\text { lysosomes }\end{array}$ & Endocytic vesicles & $\begin{array}{c}\text { Digestion of nanoparticles and } \\
\text { siRNA }\end{array}$ & $\begin{array}{c}\text { Surface conjugation of } \\
\text { ligand molecules, decrease } \\
\text { the NP size }\end{array}$ & $\begin{array}{c}\text { RGD, } \\
\text { PEGylation }\end{array}$ & [92] \\
\hline
\end{tabular}

(iii) Optimize gene expression so that the target gene is suppressed

(iv) Delivery of nanoparticles (drug carrier) to target site at an effective level

\section{Conclusions}

Despite significant progress in various nonviral-based delivery systems being at an early stage of clinical trials, significant study still remains to be overcome before the RNAi therapy can be widely used for prostate cancer gene therapy. The safety outlines of different delivery systems need to be further considered with major emphasis on decreasing the toxicity of system and elimination of nonimportant immune stimulation. The safety of enzymatically degraded products of chemically modified nanoparticles as well as nucleic acids after delivery is also important. For targeted delivery systems using ligand molecules, their immune response should also be addressed. Moreover, a detailed investigation into the major mechanisms related to avoidance of ill effects of nanoparticle vehicles is imperative.

As our horizon of prostate cancer research broadens, integration of novel treatment ideas becomes important for clinicians, biologists, and biochemical engineers. Developing gene delivery vehicles for tumor therapy, based on the unique tumor microenvironment of prostate cancer, is crucial to the delivery of clinically relevant amounts of active therapeutics to the tumor site while by-passing various biological hindrances. Nanotechnology will have an important role in realizing the goal for early diagnosis and personalized medicine for prostate cancer patients at different stages of disease, avoiding unnecessary toxicities associated with the current treatment regimens.

\section{Conflicts of Interest}

The authors declare that they have no conflict of interest in this work.

\section{Acknowledgments}

This work was supported by the National Natural Science Foundation of China (General program, nos. 51803067, 21574050, and 21774039) and China Postdoctoral Science Foundation (General program, no. 2018M630866).

\section{References}

[1] W. G. Nelson, A. M. De Marzo, and W. B. Isaacs, "Prostate cancer," The New England Journal of Medicine, vol. 349, no. 4, pp. 366-381, 2003.

[2] D. D. Chism, D. de Silva, and Y. E. Whang, "Mechanisms of acquired resistance to androgen receptor targeting drugs in castration-resistant prostate cancer," Expert Review of Anticancer Therapy, vol. 14, no. 11, pp. 1369-1378, 2014.

[3] A. Lavery, R. S. Kirby, and S. Chowdhury, "Prostate cancer," Medicine (Baltimore), vol. 44, no. 1, pp. 47-51, 2016.

[4] D. Bonci and R. De Maria, "A predictive signature for therapy assignment and risk assessment in prostate cancer," Oncoscience, vol. 2, no. 11, pp. 920-923, 2015.

[5] C. Morisson, R. Jeraj, and G. Liu, "Imaging of castrationresistant prostrate cancer: development of imaging response biomarkers," Current Opinion in Urology, vol. 23, no. 3, pp. 230-236, 2013.

[6] Q. Hu, W. Sun, C. Wang, and Z. Gu, "Recent advances of cocktail chemotherapy by combination drug delivery systems," Advanced Drug Delivery Reviews, vol. 98, pp. 19-34, 2016.

[7] A. Heidenreich, G. Aus, M. Bolla et al., "EAU Guidelines on Prostate Cancer," European Urology, vol. 53, no. 1, pp. 6880, 2008. 
[8] N. Mottet, J. Bellmunt, M. Bolla et al., "EAU Guidelines on Prostate Cancer. Part II: Treatment of Advanced, Relapsing, and Castration-Resistant Prostate Cancer," European Urology, vol. 59, no. 4, pp. 572-583, 2011.

[9] G. Attard, C. Parker, R. A. Eeles, F. Schröder, S. A. Tomlins, I. Tannock et al., "Prostate cancer," Lancet, vol. 387, pp. 7082, 2016.

[10] A. Ramos-Esquivel, C. Fernández, and Z. Zeledón, “Androgen-deprivation therapy plus chemotherapy in metastatic hormone-sensitive prostate cancer. A systematic review and meta-analysis of randomized clinical trials," Urologic Oncology: Seminars and Original Investigations, vol. 34, no. 8, pp. 335.e9-335.e19, 2016.

[11] T. W. Friedlander and C. J. Ryan, "Adrenal Androgen Synthesis Inhibitor Therapies in Castration-Resistant prostate cancer," Drug management of prostate cancer, pp. 91-100, 2010.

[12] C. A. Heinlein and C. Chang, "Androgen receptor in prostate cancer," Endocrine Reviews, vol. 25, no. 2, pp. 276-308, 2004.

[13] B. Pullar and N. Shah, "Prostate cancer," Surgery, vol. 34, no. 10, pp. 505-511, 2016.

[14] C. M. Armstrong and A. C. Gao, "Drug resistance in castration resistant prostate cancer: resistance mechanisms and emerging treatment strategies," American journal of clinical and experimental urology, vol. 3, no. 2, pp. 64-76, 2015.

[15] A. Sasikumar and K. Kamalasanan, "Nanomedicine for prostate cancer using nanoemulsion: a review," Journal of Controlled Release, vol. 260, pp. 111-123, 2017.

[16] V. Sanna and M. Sechi, "Nanoparticle therapeutics for prostate cancer treatment," Maturitas, vol. 73, no. 1, pp. 27-32, 2012.

[17] B. Haley and E. Frenkel, "Nanoparticles for drug delivery in cancer treatment," Urologic Oncology: Seminars and original investigations, vol. 26, no. 1, pp. 57-64, 2008.

[18] Y. K. Oh and T. G. Park, "siRNA delivery systems for cancer treatment," Advanced Drug Delivery Reviews, vol. 61, no. 10, pp. 850-862, 2009.

[19] H. J. Kim, A. Kim, K. Miyata, and K. Kataoka, "Recent progress in development of siRNA delivery vehicles for cancer therapy," Advanced Drug Delivery Reviews, vol. 104, pp. 6177, 2016.

[20] K. Li, H. Nejadnik, and H. E. Daldrup-Link, "Next-generation superparamagnetic iron oxide nanoparticles for cancer theranostics," Drug Discovery Today, vol. 22, no. 9, pp. 1421-1429, 2017.

[21] S. Zhang, L. Wu, J. Cao et al., "Effect of magnetic nanoparticles size on rheumatoid arthritis targeting and photothermal therapy," Colloids and Surfaces B: Biointerfaces, vol. 170, pp. 224-232, 2018.

[22] M. Nedyalkova, B. Donkova, J. Romanova, G. Tzvetkov, S. Madurga, and V. Simeonov, "Iron oxide nanoparticles In vivo/in vitro biomedical applications and in silico studies," Advances in Colloid and Interface Science, vol. 249, pp. 192212, 2017.

[23] F. Xiong, S. Huang, and N. Gu, "Magnetic nanoparticles: recent developments in drug delivery system," Drug Development and Industrial Pharmacy, vol. 44, no. 5, pp. 697-706, 2018.

[24] Y. Wang, A. Rajala, and R. V. S. Rajala, "Lipid nanoparticles for ocular gene delivery," Journal of functional biomaterials, vol. 6 , no. 2, pp. 379-394, 2015.
[25] M. Kursa, G. F. Walker, V. Roessler et al., "Novel shielded transferrin-polyethylene glycol-polyethylenimine/DNA complexes for systemic tumor-targeted gene transfer," Bioconjugate Chemistry, vol. 14, no. 1, pp. 222-231, 2003.

[26] S. H. Kim, H. Mok, J. H. Jeong, S. W. Kim, and T. G. Park, "Comparative evaluation of target-specific GFP gene silencing efficiencies for antisense ODN, synthetic siRNA, and siRNA plasmid complexed with PEI-PEG-FOL conjugate," Bioconjugate Chemistry, vol. 17, no. 1, pp. 241-244, 2006.

[27] Q. Feng, Y. Liu, J. Huang, K. Chen, J. Huang, and K. Xiao, "Uptake, distribution, clearance, and toxicity of iron oxide nanoparticles with different sizes and coatings," Scientific Reports, vol. 8, no. 1, article 19628, pp. 2082-2113, 2018.

[28] Z. Steinhart, Z. Pavlovic, M. Chandrashekhar et al., "Genome-wide CRISPR screens reveal a Wnt-FZD5 signaling circuit as a druggable vulnerability of RNF43 -mutant pancreatic tumors," Nature Medicine, vol. 23, no. 1, pp. 60-68, 2017.

[29] T. Souho, L. Lamboni, L. Xiao, and G. Yang, "Cancer hallmarks and malignancy features: gateway for improved targeted drug delivery," Biotechnology Advances, vol. 36, no. 7, pp. 1928-1945, 2018.

[30] L. Gu, A. R. Koymen, and S. K. Mohanty, "Crystalline magnetic carbon nanoparticle assisted photothermal delivery into cells using CW near-infrared laser beam," Scientific Reports, vol. 4, no. 1, pp. 1-10, 2015.

[31] T. Luo, Y. Nie, J. Lu et al., "Iron doped carbon dots based nanohybrids as a tetramodal imaging agent for gene delivery promotion and photothermal-chemodynamic cancer synergistic theranostics," Materials and Design, vol. 208, article 109878, 2021.

[32] S. Trabulo, A. Aires, A. Aicher, C. Heeschen, and A. L. Cortajarena, "Multifunctionalized iron oxide nanoparticles for selective targeting of pancreatic cancer cells," Biochimica et Biophysica Acta (BBA)-General Subjects, vol. 1861, no. 6, pp. 1597-1605, 2017.

[33] J. D. Byrne, T. Betancourt, and L. Brannon-Peppas, “Active targeting schemes for nanoparticle systems in cancer therapeutics," Advanced Drug Delivery Reviews, vol. 60, no. 15, pp. 1615-1626, 2008.

[34] M. A. Shevtsov, L. Y. Yakovleva, B. P. Nikolaev et al., "Tumor targeting using magnetic nanoparticle Hsp70 conjugate in a model of C6 glioma," Neuro-Oncology, vol. 16, no. 1, pp. 38-49, 2014.

[35] A. Kumar, T. Mastren, B. Wang, J. Hsieh, G. Hao, and X. Sun, "Design of a small-molecule drug conjugate for prostate cancer targeted theranostics," Bioconjugate chemistry, vol. 27, no. 7 , pp. 1681-1689, 2016.

[36] J. Li, L. Zheng, H. Cai et al., "Polyethyleneimine-mediated synthesis of folic acid-targeted iron oxide nanoparticles for in vivo tumor MR imaging," Biomaterials, vol. 34, no. 33, pp. 8382-8392, 2013.

[37] J. Gang, S.-B. Park, W. Hyung et al., "Magnetic poly $\varepsilon$-caprolactone nanoparticles containing $\mathrm{Fe}_{3} \mathrm{O}_{4}$ and gemcitabine enhance anti-tumor effect in pancreatic cancer xenograft mouse model," Journal of Drug Targeting, vol. 15, no. 6, pp. 445-453, 2007.

[38] W. Sun, J. Yang, J. Zhu et al., "Immobilization of iron oxide nanoparticles within alginate nanogels for enhanced MR imaging applications," Biomaterials Science, vol. 4, no. 10, pp. 1422-1430, 2016. 
[39] J. H. Zhou, L. Huang, W. W. Wang et al., "Prostate cancer Targeted MRI Nanoprobe Based on Superparamagnetic iron Oxide and Copolymer of Poly (Ethylene Glycol) and Polyethyleneimin," Chinese Science Bulletin, vol. 54, no. 18, pp. 3137-3146, 2009.

[40] A. Saraswathy, S. S. Nazeer, M. Jeevan et al., "Citrate coated iron oxide nanoparticles with enhanced relaxivity for in vivo magnetic resonance imaging of liver fibrosis," Colloids and Surfaces B: Biointerfaces, vol. 117, pp. 216-224, 2014.

[41] Y. Fan, R. Guo, X. Shi et al., "Modified nanoemulsions with iron oxide for magnetic resonance imaging," Nanomaterials, vol. 6, no. 12, p. 223, 2016.

[42] J. Li, Y. Hu, J. Yang et al., "Hyaluronic acid-modified $\mathrm{Fe}_{3} \mathrm{O}_{4} @ \mathrm{Au}$ core/shell nanostars for multimodal imaging and photothermal therapy of tumors," Biomaterials, vol. 38, pp. 10-21, 2015.

[43] P. K. B. Nagesh, N. R. Johnson, V. K. N. Boya et al., "PSMA targeted docetaxel-loaded superparamagnetic iron oxide nanoparticles for prostate cancer," Colloids and Surfaces B: Biointerfaces, vol. 144, pp. 8-20, 2016.

[44] A. Kiessling, R. Wehner, S. Füssel, M. Bachmann, M. P. Wirth, and M. Schmitz, "Tumor-associated antigens for specific immunotherapy of prostate cancer," Cancers (Basel), vol. 4, no. 1, pp. 193-217, 2012.

[45] Z. Wang, G. Liu, H. Zheng, and X. Chen, "Rigid nanoparticlebased delivery of anti-cancer siRNA: challenges and opportunities," Biotechnology Advances, vol. 32, no. 4, pp. 831-843, 2014.

[46] Y. Dong, D. J. Siegwart, and D. G. Anderson, "Strategies, design, and chemistry in siRNA delivery systems," Advanced Drug Delivery Reviews, vol. 144, pp. 133-147, 2019.

[47] S. Senapati, A. K. Mahanta, S. Kumar, and P. Maiti, "Controlled drug delivery vehicles for cancer treatment and their performance," Signal transduction and targeted therapy, vol. 3, no. 1, pp. 1-19, 2018.

[48] X. Wang, L. Zhu, X. Hou, L. Wang, and S. Yin, "Polyethylenimine mediated magnetic nanoparticles For combined intracellular imaging, siRNA delivery and anti-tumor therapy," RSC advances, vol. 5, no. 123, pp. 101569-101581, 2015.

[49] H. Y. Yoon, S. Son, S. J. Lee et al., "Glycol chitosan nanoparticles as specialized cancer therapeutic vehicles: sequential delivery of doxorubicin and Bcl-2 siRNA," Scientific Reports, vol. 4, no. 1, pp. 1-12, 2014.

[50] B. K. Biswal, N. B. Debata, and R. S. Verma, "Development of a targeted siRNA delivery system using FOL-PEG-PEI conjugate," Molecular Biology Reports, vol. 37, no. 6, pp. 29192926, 2010.

[51] S. Xiang, H. Tong, Q. Shi et al., "Uptake mechanisms of nonviral gene delivery," Journal of Controlled Release, vol. 158, no. 3, pp. 371-378, 2012.

[52] A. Ewe, S. Höbel, C. Heine et al., "Optimized polyethylenimine (PEI) -based nanoparticles for siRNA delivery, analyzed in vitro and in an ex vivo tumor tissue slice culture model," Drug Delivery and Translational Research, vol. 7, no. 2, pp. 206-216, 2017.

[53] A. Harada, H. Togawa, and K. Kataoka, "Physicochemical properties and nuclease resistance of antisense- oligodeoxynucleotides entrapped in the core of polyion complex micelles composed of poly(ethylene glycol)-poly(l-Lysine) block copolymers," European Journal of Pharmaceutical Sciences, vol. 13, no. 1, pp. 35-42, 2001.
[54] A. Ewe, S. Przybylski, J. Burkhardt, A. Janke, D. Appelhans, and A. Aigner, "A novel tyrosine-modified low molecular weight polyethylenimine (P10Y) for efficient siRNA delivery in vitro and in vivo," Journal of Controlled Release, vol. 230, pp. 13-25, 2016.

[55] J. Park, J. Park, Y. Pei, J. Xu, and Y. Yeo, "Pharmacokinetics and biodistribution of recently-developed siRNA nanomedicines," Advanced Drug Delivery Reviews, vol. 104, pp. 93-109, 2016.

[56] S. Hosseinkhani, Samadikhah, Majidi, and Nikkhah, "Preparation, characterization, and efficient transfection of cationic liposomes and nanomagnetic cationic liposomes," International Journal of Nanomedicine, vol. 6, pp. 2275-2283, 2011.

[57] J. Peng, F. Zou, L. Liu et al., "Preparation and characterization of PEG- PEI/ $/ \mathrm{Fe}_{3} \mathrm{O}_{4}$ nano-magnetic fluid by co-precipitation method," Transactions of nonferrous metals society of China, vol. 18, no. 2, pp. 393-398, 2008.

[58] S. Zhen, Y. Takahashi, S. Narita, Y.-C. Yang, and X. Li, “Targeted delivery of CRISPR/Cas9 to prostate cancer by modified gRNA using a flexible aptamer-cationic liposome," Oncotarget, vol. 8, no. 6, article 14072, pp. 9375-9387, 2017.

[59] Z. Chen, F. Liu, Y. Chen et al., "Targeted delivery of CRISPR/Cas9-mediated cancer gene therapy via liposome-templated hydrogel nanoparticles," Advanced Functional Materials, vol. 27, no. 46, article 1703036, pp. 1-9, 2017.

[60] W. Y. Hwang, Y. Fu, D. Reyon et al., "Efficient genome editing in zebrafish using a CRISPR-Cas system," Nature Biotechnology, vol. 31, no. 3, pp. 227-229, 2013.

[61] F. A. Ran, P. D. Hsu, J. Wright, V. Agarwala, D. A. Scott, and F. Zhang, "Genome engineering using the CRISPR-Cas9 system," Nature protocols, vol. 8, no. 11, pp. 2281-2308, 2013.

[62] Y. I. Jo, B. Suresh, H. Kim, and S. Ramakrishna, "CRISPR/Cas9 system as an innovative genetic engineering tool: enhancements in sequence specificity and delivery methods," Biochimica et Biophysica Acta (BBA)-Reviews on Cancer, vol. 1856, no. 2, pp. 234-243, 2015.

[63] L. Xiao-Jie, X. Hui-Ying, K. Zun-Ping, C. Jin-Lian, and J. LiJuan, "CRISPR-Cas9: a new and promising player in gene therapy," Journal of Medical Genetics, vol. 52, no. 5, pp. 289-296, 2015.

[64] C. Liu, L. Zhang, H. Liu, and K. Cheng, "Delivery strategies of the CRISPR-Cas9 gene-editing system for therapeutic applications," Journal of Controlled Release, vol. 266, pp. 17-26, 2017.

[65] A. Li, J. Qiu, B. Zhou et al., "The gene transfection and endocytic uptake pathways mediated by PEGylated PEIentrapped gold nanoparticles," Arabian Journal of Chemistry, vol. 13, no. 1, pp. 2558-2567, 2020.

[66] S. C. McBain, H. H. P. Yiu, A. el Haj, and J. Dobson, "Polyethyleneimine functionalized iron oxide nanoparticles as agents for DNA delivery and transfection," Journal of Materials Chemistry, vol. 17, no. 24, p. 2561, 2007.

[67] B. Tang, B. Tang, Cheang, S. Wang, and Pro Xu, "Promising plasmid DNA vector based on APTES-modified silica nanoparticles," International Journal of Nanomedicine, vol. 7, pp. 1061-1067, 2012.

[68] Z. Zhang, L. Song, J. Dong et al., “A promising combo gene delivery system developed from (3-Aminopropyl) triethoxysilane-modified iron oxide nanoparticles and cationic polymers," Journal of Nanoparticle Research, vol. 15, no. 5, 2013. 
[69] A. K. Bordbar, A. A. Rastegari, R. Amiri, E. Ranjbakhsh, M. Abbasi, and A. R. Khosropour, "Characterization of modified magnetite nanoparticles for albumin immobilization," Biotechnology Research International, vol. 2014, Article ID 705068, 6 pages, 2014.

[70] F. Hosseini, M. Sadjadi, and N. Farhadyar, " $\mathrm{Fe}_{3} \mathrm{O}_{4}$ nanoparticles modified with APTES as the carrier for (+)-(S)-2-(6methoxynaphthalen-2-yl) propanoic acid (naproxen) and (RS) 2-(3-benzoylphenyl)-propionic acid (ketoprofen) drug," Oriental Journal of Chemistry, vol. 30, no. 4, pp. 1609-1618, 2014.

[71] A. H. Nguyen, G. N. Abdelrasoul, D. Lin et al., "Polyethylenimine-coated iron oxide magnetic nanoparticles for high efficient gene delivery," Applied Nanoscience, vol. 8, no. 4, pp. 811-821, 2018.

[72] T. Zhang, X. Xue, D. He, and J. T. Hsieh, “A prostate cancertargeted polyarginine-disulfide linked PEI nanocarrier for delivery of microRNA," Cancer Letters, vol. 365, no. 2, pp. 156-165, 2015.

[73] J. Fredsøe, A. K. I. Rasmussen, A. R. Thomsen et al., "Diagnostic and prognostic microRNA biomarkers for prostate cancer in cell-free urine," European Urology Focus, vol. 4, no. 6, pp. 825-833, 2018.

[74] F. Li and R. I. Mahato, "MicroRNAs and drug resistance in prostate cancers," Molecular pharmaceutics, vol. 11, no. 8, pp. 2539-2552, 2014.

[75] K. Khanmi, S. Ignacimuthu, and M. G. Paulraj, "MicroRNA in prostate cancer," Clinica Chimica Acta, vol. 451, pp. 154160, 2015.

[76] E. Ottley and E. Gold, "MicroRNA and non-canonical TGF- $\beta$ signalling: implications for prostate cancer therapy," Critical Reviews in Oncology/Hematology, vol. 92, no. 1, pp. 49-60, 2014.

[77] H. Wang, Y. Jiang, H. Peng, Y. Chen, P. Zhu, and Y. Huang, "Recent progress in microRNA delivery for cancer therapy by non-viral synthetic vectors," Advanced Drug Delivery Reviews, vol. 81, pp. 142-160, 2015.

[78] V. de Franciscis, "A Theranostic "SMART" Aptamer for Targeted Therapy of Prostate Cancer," Molecular Therapy, vol. 22, no. 11, pp. 1886-1888, 2014.

[79] G. Zhou, O. Latchoumanin, M. Bagdesar et al., "Aptamerbased therapeutic approaches to target cancer stem cells," Theranostics, vol. 7, no. 16, pp. 3948-3961, 2017.

[80] J. Zhou and J. Rossi, "Aptamers as targeted therapeutics: current potential and challenges," Nature Reviews. Drug Discovery, vol. 16, no. 3, pp. 181-202, 2017.

[81] B. J. Hicke and A. W. Stephens, "Escort aptamers: a delivery service for diagnosis and therapy," The Journal of Clinical Investigation, vol. 106, no. 8, pp. 923-928, 2000.

[82] O. C. Farokhzad, S. Jon, A. Khademhosseini, T. N. T. Tran, D. A. LaVan, and R. Langer, "Nanoparticle-aptamer bioconjugates: a new approach for targeting prostate cancer cells," Cancer Research, vol. 64, no. 21, pp. 7668-7672, 2004.

[83] A. Z. Wang, V. Bagalkot, C. C. Vasilliou et al., "Superparamagnetic iron oxide nanoparticle-aptamer bioconjugates for combined prostate cancer imaging and therapy," ChemMedChem, vol. 3, no. 9, pp. 1311-1315, 2008.

[84] E. Paolicchi, F. Gemignani, M. Krstic-Demonacos, S. Dedhar, L. Mutti, and S. Landi, "Targeting hypoxic response for cancer therapy," Oncotarget, vol. 7, no. 12, pp. 13464-13478, 2016.
[85] H. Zhu, L. Zhang, Y. Liu et al., “Aptamer-PEG-modified $\mathrm{Fe}_{3} \mathrm{O}_{4} @ \mathrm{Mn}$ as a novel T1- and T2- dual-model MRI contrast agent targeting hypoxia-induced cancer stem cells," Scientific Reports, vol. 6, no. 1, pp. 1-12, 2016.

[86] H. Yin, R. L. Kanasty, A. A. Eltoukhy, A. J. Vegas, J. R. Dorkin, and D. G. Anderson, "Non-viral vectors for gene-based therapy," Nature Reviews. Genetics, vol. 15, no. 8, pp. 541$555,2014$.

[87] B. Shi, M. Zheng, W. Tao et al., "Challenges in DNA delivery and recent advances in multifunctional polymeric DNA delivery systems," Biomacromolecules, vol. 18, no. 8, pp. 2231-2246, 2017.

[88] Z. Tang, Y. Wang, P. Podsiadlo, and N. A. Kotov, "Biomedical applications of layer-by-layer assembly: from biomimetics to tissue engineering," Advanced Materials, vol. 18, no. 24, pp. 3203-3224, 2006.

[89] Y. Liu, S. An, J. Li et al., "Brain-targeted co-delivery of therapeutic gene and peptide by multifunctional nanoparticles in Alzheimer's disease mice," Biomaterials, vol. 80, pp. 33-45, 2016.

[90] P. P. Adiseshaiah, R. M. Crist, S. S. Hook, and S. E. Mcneil, "Nanomedicine strategies to overcome the pathophysiological barriers of pancreatic cancer," Nature reviews Clinical oncology, vol. 13, no. 12, pp. 750-765, 2016.

[91] F. Yuan, M. Dellian, D. Fukumura et al., "Vascular permeability in a human tumor xenograft: molecular size dependence and cutoff size," Cancer Research, vol. 55, pp. 37523756, 1995.

[92] R. K. Jain, "Transport of molecules, particles, and cells in solid tumors," Annual Review of Biomedical Engineering, vol. 1, no. 1, pp. 241-263, 1999.

[93] J. L. Au, B. Z. Yeung, M. G. Wientjes, Z. Lu, and M. G. Wientjes, "Delivery of cancer therapeutics to extracellular and intracellular targets: Determinants, barriers, challenges and opportunities," Advanced drug delivery reviews, vol. 97, pp. 280-301, 2016.

[94] H. Maeda, "Tumor-selective delivery of macromolecular drugs via the EPR effect: Background and Future Prospects," Bioconjugate Chemistry, vol. 21, no. 5, pp. 797-802, 2010.

[95] A. de Fougerolles, H. P. Vornlocher, J. Maraganore, and J. Lieberman, "Interfering with disease: a progress report on siRNA-based therapeutics," Nature Reviews. Drug Discovery, vol. 6, no. 6, pp. 443-453, 2007.

[96] H. Shen, T. Sun, and M. Ferrari, "Nanovector delivery of siRNA for cancer therapy," Cancer Gene Therapy, vol. 19, no. 6, pp. 367-373, 2012.

[97] J. Guo, J. C. Evans, and C. M. O’Driscoll, “Delivering RNAi therapeutics with non-viral technology: a promising strategy for prostate cancer?," Trends in Molecular Medicine, vol. 19, no. 4, pp. 250-261, 2013.

[98] K. J. Scanlon, "Cancer gene therapy: challenges and opportunities," Anticancer Research, vol. 24, no. 2A, pp. 501-504, 2004.

[99] G. Cavallaro, C. Sardo, E. F. Craparo, B. Porsio, and G. Giammona, "Polymeric nanoparticles for siRNA delivery: production and applications," International Journal of Pharmaceutics, vol. 525, no. 2, pp. 313-333, 2017.

[100] K. A. Ahmed, B. J. Davis, T. M. Wilson, G. A. Wiseman, M. J. Federspiel, and J. C. Morris, "Progress in gene therapy for prostate cancer," Frontiers in Oncology, vol. 2, pp. 1-7, 2012. 